\title{
Photo-oxidation modulates green fern spore longevity during dry storage
}

\author{
Daniel Ballesteros $^{1,2}\left(\right.$ D $\cdot$ Sonam Narayan ${ }^{1} \cdot$ Boby Varghese $^{1} \cdot$ Sershen $^{1}$ (i)
}

Received: 25 September 2017 / Accepted: 13 December 2017 / Published online: 4 January 2018

(C) The Author(s) 2018. This article is an open access publication

\begin{abstract}
Desiccation tolerance and longevity of plant propagules in the dry state have significant implications for biotechnological applications. In this study fern spores were used as a unicellular model to characterize some of the mechanisms of ageing during dry storage of plant propagules (at relative humidity ca. 15\%). More specifically, we compared the potential relationships among indicators of photo-oxidative stress and spore viability during dry storage between green (chlorophyllous) spores of Todea barbara and non-green spores of Christella dentata. Green spores stored under the light aged faster than those stored in the dark, and faster than light- and dark-stored non-green spores of $C$. dentata. This rapid ageing in light-stored green spores was associated with significantly lower antioxidant activity (relative to time zero and dark-stored spores) during storage, and a burst of hydrogen peroxide during the latter stages of storage, which was not a feature of dark-stored spores. We attribute these signs of enhanced oxidative-stress mediated ageing in light-stored spores to photo-oxidative processes, similar to those described in other homoiochlorophyllous organisms. Additionally, high antioxidant activity and low levels of reactive oxygen species in green spores compared with non-green spores suggests differing mechanisms of coping with life in the dry state.
\end{abstract}

Keywords Ageing $\cdot$ Antioxidants $\cdot$ Christella dentata $\cdot$ Desiccation $\cdot$ Reactive oxygen species $\cdot$ Todea barbara

\section{Introduction}

The study of desiccation tolerance and longevity in the dry state in plant propagules is not only important to understand the success of plants on terrestrial Earth and the laws governing life on it, but also has implications on biotechnological applications in diverse fields such as medicine, crop improvement, and genetic diversity preservation (Leprince and Buitink 2010). During desiccation, cells of desiccation tolerant plant tissues considerably reduce their volume as the cytoplasm increases its viscosity up to a point at which

Communicated by Sergio J. Ochatt.

Daniel Ballesteros

d.ballesteros@kew.org

1 Plant Germplasm Conservation Research, School of Life Sciences, University of KwaZulu-Natal, South Ring Road, Westville Campus, Durban 4001, South Africa

2 Present Address: Royal Botanic Gardens, Kew, Welcome Trust Millennium Building in Wakehurst Place, Ardingly, West Sussex RH17 6TN, UK it resembles a solid (Leprince and Buitink 2015; Walters 2015). This change from fluid to solid is known as vitrification glass transition from solid to fluid and the resulting (amorphous) solid is often referred to as a glass. Desiccation tolerant organisms survive the compressive forces and cell volume reduction before glasses are formed (Leprince and Buitink 2015; Walters 2015; Ballesteros et al. 2017), and after vitrification they ideally should survive a relatively long time in the glassy state (e.g. Walters et al. 2005; Ballesteros et al. 2017). However, longevity in the glassy state is life form and species dependent (e.g. Walters et al. 2005; Hoekstra 2005; Ballesteros et al. 2017), and although mechanisms of ageing in the glassy state are often associated with oxidative stress (Walters et al. 2010) little is known about how these mechanisms may differ with life form and propagule post-harvest physiology.

Propagule desiccation tolerance and longevity are intimately related (Ballesteros et al. 2017); for example, both traits develop consecutively during late embryo development in seeds (Verdier et al. 2013; Pereira Lima et al. 2017). In angiosperms, desiccation tolerance is usually expressed in reproductive cells, as in seeds and pollen (Franchi et al. 
2011; Gaff and Oliver 2013; Hoekstra 2005). This ability to survive extreme desiccation is an ancestral trait that most likely derived from the desiccation tolerance expressed in spores of antecedent taxa, such as ferns (Gaff and Oliver 2013). Hence, it could be reasonable to suggest that the basic pollen/embryo mechanisms of desiccation tolerance and longevity might be based on those found in fern spores. Fern spores are unicellular propagules that are usually classified as green (chlorophyllous) or non-green (non-chlorophyllous) depending on their colour at maturity (Sundue et al. 2011). Both spore types have similar tolerance to desiccation and this level of tolerance is comparable to that exhibited by most desiccation tolerant seeds and pollen (Pence 2000; Walters et al. 2005; Li and Shi 2014, 2015; Ballesteros et al. 2017). When dried to ambient conditions (usually at $20-25{ }^{\circ} \mathrm{C}$ and relative humidity between 30 and $60 \%$ ) green and non-green spores form glasses but under such conditions the former generally age faster (Lloyd and Klekowski 1970; Hoekstra 2005; Li and Shi 2014, 2015; Ballesteros et al. 2017). The unicellular nature of fern spores makes them a very convenient model to study desiccation tolerance and longevity in dry plant germplasm, as the complications of data interpretation related to tissue complexity are avoided (Ballesteros et al. 2012, 2017). However, little is known about the mechanisms that modulate longevity in fern spores and whether viability loss in green and non-green spores are governed by the same mechanisms (Ballesteros 2010).

The extremely short viability of the green spores of Equisetum hyemale has been attributed to the inability to recover core function of part of the photosynthetic apparatus upon rehydration after dry storage (Lebkuecher 1997). In other organisms tolerant to desiccation that retain chlorophyll in the dry state light is absorbed by the pigments of the photosynthetic apparatus, and it is known that when water is absent, free radicals are produced and threaten to oxidise components of the photosynthetic apparatus (Heber et al. 2006; Kranner et al. 2008). In this sense, photo-oxidative stress has been related to ageing of dry chlorophyllous seeds through damage to thylakoid membranes (Roqueiro et al. 2010). Hence, we test here the hypothesis that the fast ageing of green spores after drying and when in the dry state could result from an imbalance on free radicals and reactive oxygen species (ROS) and/or from a reduced antioxidant protection (Kranner et al. 2010), particularly when spores are stored in the light. Alternatively, we do not expect lightinduced deterioration in non-green spores, as they generally lack photosynthetic apparatus (Sundue et al. 2011).

To that end, we have tested whether photo-oxidative stress is driving the fast ageing occurring in green spores during dry storage by comparing levels of ROS production and antioxidant activity between green and non-green spores before and after drying below the moisture contents when the glass is formed and during storage in the glassy state under light and dark conditions. These measures of oxidative metabolism were in turn related to germination capacity, over a range of storage times.

\section{Materials and methods}

\section{Plant materials}

Green and non-green spores were obtained from the ferns Todea barbara (L.) T. Moore (Osmundaceae) and Christella dentata (Forssk.) Brownsey and Jermy (Thelypteridaceae), respectively. Mature fronds were collected in the Glenholme Nature Reserve in Kloof, KwaZulu-Natal, South Africa, transported on the same day to the laboratory, and placed between sheets of paper until sporangial dehiscence $\left(20-23{ }^{\circ} \mathrm{C}\right.$ and $\left.75 \% \mathrm{RH}\right)$. Dehisced green and non-green spores were collected after the fronds were left in place for 5-7 (T. barbara)/7-10 (C. dentata) days. The spores were then sieved to remove residual particles, transferred into vials, and stored at $-80{ }^{\circ} \mathrm{C}$ to preserve their original viability (Ballesteros et al. 2011, 2012) until the experiments were initiated (about 4 months after spore collection). Spores were thawed from $-80{ }^{\circ} \mathrm{C}$ by placing the vials in a $40{ }^{\circ} \mathrm{C}$ water bath for $5 \mathrm{~min}$.

\section{Desiccation and storage of fern spores}

Green and non-green spores were initially dried by equilibrating them for $24 \mathrm{~h}$ at $4{ }^{\circ} \mathrm{C}$ over a saturated $\mathrm{LiCl}$ salt solution (RH of 15\%; Ballesteros and Walters 2007a). Thereafter, spores were stored in chambers containing the same solution but placed at a constant temperature of $20 \pm 2{ }^{\circ} \mathrm{C}$ (RH in the chamber decreased to $13 \%$ due to the temperature increase; Ballesteros and Walters 2007a) under constant dark conditions or under a $16-\mathrm{h}$ photoperiod at $200 \mu \mathrm{mol} \mathrm{m} \mathrm{m}^{-2} \mathrm{~s}^{-1}$ at $20 \pm 2{ }^{\circ} \mathrm{C}$. Viability (as total germination proportion), extracellular superoxide and hydrogen peroxide production, total aqueous antioxidant activity (TAA) and electrolyte leakage levels were measured before and after initial desiccation and for selected storage times ranging from 1 to 42 days. All biochemical assays were performed in triplicate for each species-treatment-storage time combination and the specific methods used to measure each of these parameters are detailed below.

\section{Water content determination}

Water content of spores was determined gravimetrically before and after desiccation, at periodic intervals during storage for three samples of $5-10 \mathrm{mg}$ of spores from each treatment. After fresh mass determination, spores were dried in an oven at $80{ }^{\circ} \mathrm{C}$ for $72 \mathrm{~h}$ for dry mass (DM) 
determination; water contents were expressed on a DM basis ( $\mathrm{g} \mathrm{H}_{2} \mathrm{O} \mathrm{g}^{-1} \mathrm{DM}$ ).

\section{Germination of fern spores}

For each storage time, a subsample of about 1-3 mg of spores was used for the viability assay. Spores of both species were germinated on the mineral culture medium for fern spores described by Dyer (1979), enriched with $100 \mathrm{U} \mathrm{mL}^{-1}$ of the fungicide Nystatin (Sigma-Aldrich, MO, USA), and solidified with 1.1\% agar (e.g. Ballesteros et al. 2012, 2017). Four Petri dishes were sowed with the subsample of spores (i.e. 1-3 mg divided across the four dishes) and were placed at a constant temperature of $20 \pm 2{ }^{\circ} \mathrm{C}$ under constant dark conditions or under a $16-\mathrm{h}$ photoperiod at $200 \mu \mathrm{mol} \mathrm{m}^{-2} \mathrm{~s}^{-1}$ at $20 \pm 2{ }^{\circ} \mathrm{C}$. Germination percentage after 15 and 30 days of culture was used to quantify viability of green and non-green spores, respectively (after Ballesteros et al. 2011, 2012, 2017). Germination was calculated for each plate by counting the number of germinated spores that were observed out of 100 spores selected at random, at $\times 40$ magnification under a light microscope. Germinated spores were identified by the protrusion of the rhizoid or emergence of the first chlorophyllic cell (e.g. Ballesteros et al. 2017).

\section{Determination of superoxide levels}

For the determination of extracellular superoxide $\left(\mathrm{O}_{2}{ }^{-{ }^{-}}\right)$production, $50 \mathrm{mg}$ (per replicate, $\mathrm{n}=3$ ) of spores were placed in $1 \mathrm{~mL}$ of $1 \mathrm{mM}$ epinephrine solution at $\mathrm{pH} 7$ according to Misra and Fridovich (1972). This was shaken at $60 \mathrm{rpm}$ for $10 \mathrm{~min}$ in dark after which it was centrifuged at $14,000 \mathrm{rpm}$ (Hermle Labortechnik, Germany) for 10 min and left to stand for a further $10 \mathrm{~min}$. The absorbance of the solution was then read at $470 \mathrm{~nm}$ using a UV-Vis spectrophotometer (Cary 50 Conc UV-Vis spectrophotometer, Varian). Extracellular $\mathrm{O}_{2}{ }^{--}$production was expressed as $\mathrm{pmol} \mathrm{g}^{-1} \mathrm{DM} \mathrm{s}^{-1}$ (Varghese et al. 2011).

\section{Determination of extracellular hydrogen peroxide levels}

For the determination of extracellular hydrogen peroxide $\left(\mathrm{H}_{2} \mathrm{O}_{2}\right)$ production, a working reagent was prepared by mixing one part of Reagent A (comprising $25 \mathrm{mmol} \mathrm{L}^{-1} \mathrm{FeSO}_{4}$, $25 \mathrm{mmol} \mathrm{L}^{-1}\left(\mathrm{NH}_{4}\right)_{2} \mathrm{SO}_{4}$, and $\left.2.5 \mathrm{~mol} \mathrm{~L}^{-1} \mathrm{H}_{2} \mathrm{SO}_{4}\right)$ and 100 parts of Reagent B (containing $125 \mu \mathrm{mol} \mathrm{L}^{-1}$ xylenol orange and $100 \mathrm{mmol} \mathrm{L}^{-1}$ sorbitol), which was stirred for $15 \mathrm{~min}$ prior to performing the assay. Then $50 \mathrm{mg}$ (per replicate, $\mathrm{n}=3$ ) of spores were placed in $2 \mathrm{~mL}$ of this solution, which was shaken for $10 \mathrm{~min}$ at $60 \mathrm{rpm}$ in the dark, centrifuged at $14,000 \mathrm{rpm}$ for $10 \mathrm{~min}$, and left to stand for a further $10 \mathrm{~min}$. The absorbance of the solution was then read at $560 \mathrm{~nm}$. The extracellular $\mathrm{H}_{2} \mathrm{O}_{2}$ content was expressed as pmol g ${ }^{-1} \mathrm{DM}$ $\mathrm{s}^{-1}$ as per Gay and Gebicki (2000).

\section{Determination of total aqueous antioxidant activity}

TAA activity was measured on $50 \mathrm{mg}$ (per replicate, $\mathrm{n}=3$ ) of spores, which were ground in liquid nitrogen with $10 \mathrm{mg}$ polyvinylpyrrolidone and $1 \mathrm{~mL}$ phosphate extraction buffer as described by Berjak et al. (2011). The contents were transferred into chilled Eppendorf tubes, which were vortexed at $5 \mathrm{~min}$ intervals for $15 \mathrm{~min}$ and centrifuged at $14,000 \mathrm{rpm}$ at $4{ }^{\circ} \mathrm{C}$ for $1 \mathrm{~h}$. The supernatant was then decanted and placed on ice. Thereafter, the TAA activity in the supernatant was calorimetrically estimated using the ABTS decolourisation assay. A known volume of the supernatant was tested for its antioxidant potential in a $1 \mathrm{~mL}$ ABTS radical solution ( $7 \mathrm{mM} \mathrm{ABTS}$ and $2.45 \mathrm{mM} \mathrm{K}_{2} \mathrm{~S}_{2} \mathrm{O}_{8}$ ) diluted with phosphate buffer saline. The decline in absorbance was read at $734 \mathrm{~nm}$ using a spectrophotometer and total antioxidant activity was estimated as trolox equivalents, using a standard curve. The results were expressed as TAA per gram of tissue extracted and expressed as Trolox equivalent $\mathrm{g}^{-1} \mathrm{FM}$ (Re et al. 1999).

\section{Differential scanning calorimetry}

Thermal behaviour of freshly harvested fern spores was measured using differential scanning calorimetry (DSC). This experiment was conducted to characterize the physical status of the cytoplasm of fern spores before and after drying, which may in turn have influenced their storage behaviour. Approximately 3-10 mg of sample, held at RH ranging from 5 to $95 \%$, was hermetically sealed into Tzero aluminium pans (TA Instruments, New Castle, DE, USA). First and second order transitions of water and triacylglycerols (TAG) were assessed using a DSC Q2000 (TA Instruments, New Castle, DE, USA), cooled using liquid nitrogen. Instruments were calibrated at a scanning rate of $10{ }^{\circ} \mathrm{C} \mathrm{min}{ }^{-1}$ for temperature using methylene chloride $\left(-95^{\circ} \mathrm{C}\right)$ and indium $\left(156.6{ }^{\circ} \mathrm{C}\right)$ standards and for energy using indium (28.54 $\mathrm{J} \mathrm{g}^{-1}$ ) (Ballesteros and Walters 2007b). Samples were cooled and heated between -150 and $+90{ }^{\circ} \mathrm{C}$ at $10{ }^{\circ} \mathrm{C} \mathrm{min}{ }^{-1}$ and thermal events were assessed during cooling and warming scans. Enthalpy $(\Delta \mathrm{H})$ of first order transitions (i.e., crystallization, crystal melting or recrystallization) was calculated from the area encompassed by the peak and the baseline and the onset temperature was determined from the intersection between the baseline and a line drawn from the steepest portion of the transition peak. Second order transitions in heating scans were identified as glass melting events, and the glass transition temperature ( $\mathrm{Tg}$ ) was assigned as the midpoint in the displacement of power during the scan, as previously performed for pollen (Buitink et al. 1996) and fern spores (Ballesteros et al. 2017). 
The glass transition temperature ( $\mathrm{Tg}$ ) indicates that the fern cytoplasm changes from a solid state (known as glass) to a more fluid state upon warming that allows diffusive motion (Buitink et al. 1996). All analyses were performed using TA Universal analysis 2000 version 4.5 .

\section{Statistical analysis}

All survival data were treated as proportion data as in Ballesteros et al. (2017). Significant effects of storage time on spore viability were confirmed using a general linear model (GLM) with logit function and a binomial distribution available in the Genstat software 14.2 (VSN International Ltd, 2011). The effective dose function using a logit link in the probit analysis of Genstat was then used to calculate deterioration time to $50 \%$ of the maximum germination of the species (P50). This analysis enabled us to calculate standard error of P50 and to compare longevities within species at different storage conditions. Significant differences in the levels of extracellular $\mathrm{O}_{2}{ }^{-}$and $\mathrm{H}_{2} \mathrm{O}_{2}$, electrolyte leakage and TAA between spores before and after drying within species, and between green and spores for the different lightstorage time combinations were assessed using T-test and ANOVA, respectively. A Shapiro-Wilks test was used to assess whether biochemical data were normally distributed and where data were non-parametric a Kruskal-Wallis test was used to make the comparisons described above. All statistical tests were performed with SPSS Statistics software (IBM; version 21). In addition, the levels of $\mathrm{O}_{2}{ }^{--}, \mathrm{H}_{2} \mathrm{O}_{2}$, electrolyte leakage and TAA were regressed over time, and significance of these regressions was tested using Excel and an $\mathrm{F}$ distribution model with probability set at 0.05 .

\section{Results}

\section{Water content of fern spores after desiccation and storage}

Fern spores dried rapidly during moisture equilibration at $15 \% \mathrm{RH}$ and $4{ }^{\circ} \mathrm{C}$. For example, during the first $8 \mathrm{~h}$ water content (WC) of T. barbara spores decreased from ca. 0.157 (at shedding) to ca. $0.051 \mathrm{~g} \mathrm{~g}^{-1}$ (Fig. 1), and remained at that level during the rest of the moisture equilibration period. When spores were moved to $13 \% \mathrm{RH}$ and $20{ }^{\circ} \mathrm{C}$ to initiate the storage treatments the WC reduced slightly to ca. $0.036 \mathrm{~g} \mathrm{~g}^{-1}$ in a few hours (data not shown) but remained constant throughout the storage experiment (Fig. 1, inset). Water content of $C$. dentata decreased from 0.129 to $0.036 \mathrm{~g} \mathrm{~g}^{-1}$ during moisture equilibration, and when moved to $13 \% \mathrm{RH}$ and $20{ }^{\circ} \mathrm{C}$ reduced very slightly to ca. $0.033 \mathrm{~g} \mathrm{~g}^{-1}$, where it remained for the duration of the storage experiment (data not shown).

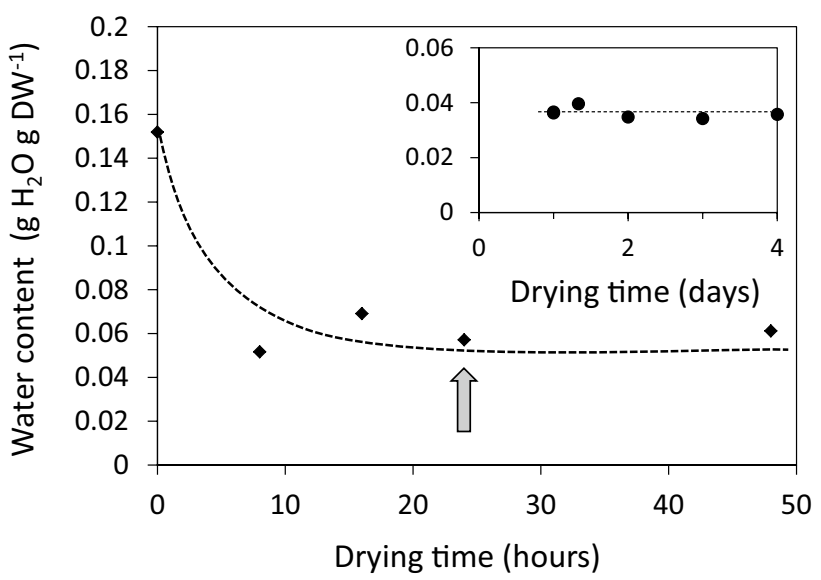

Fig. 1 Desiccation of spores of the fern T. barbara during equilibration at $15 \% \mathrm{RH}$ and $4{ }^{\circ} \mathrm{C}$. After $24 \mathrm{~h}$ spores were moved to $13 \% \mathrm{RH}$ and $20{ }^{\circ} \mathrm{C}$, and water contents during 4 days of storage are showed in the inset. Time zero for the ageing experiment was considered to be $24 \mathrm{~h}$ at $15 \% \mathrm{RH}$ (grey arrow)

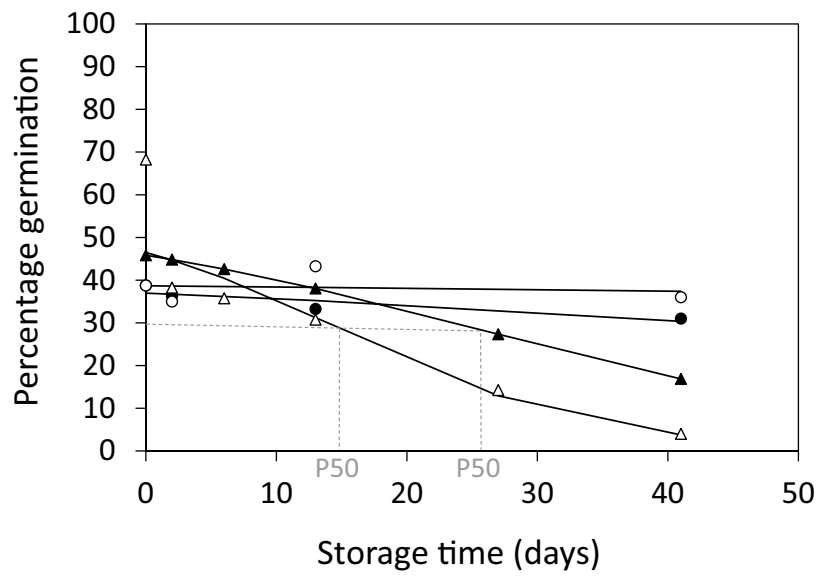

Fig. 2 Germination time courses of T. barbara (triangles) and $C$. dentata (circles) spores stored in the dark (closed symbols) or in the light (open symbols). Lines represent the data fitted to a GLM model with a logit function. Time to germination to decrease to $50 \%$ (P50) is indicated for T. barbara spores with grey dotted lines

\section{Germination of fern spores after desiccation and over storage time}

After harvest, germinability for the green (T. barbara) and non-green (C. dentata) spores was $57 \pm 6$ and $46 \pm 13 \%$, respectively (Fig. 3a). The initial $24 \mathrm{~h}$ of drying increased germination to $68 \pm 3 \%$ in the green spores of $T$. barbara $(\mathrm{P}<0.05$ in binomial tests, Fig. 3a) but did not significantly change the germinability of the non-green spores (Fig. 3a). Deterioration time courses during storage of green and nongreen spores under light and dark conditions were fitted to a GLM model with logit function and are shown in Fig. 2. Except for $C$. dentata spores stored in the light $(\mathrm{P}=0.136)$, 

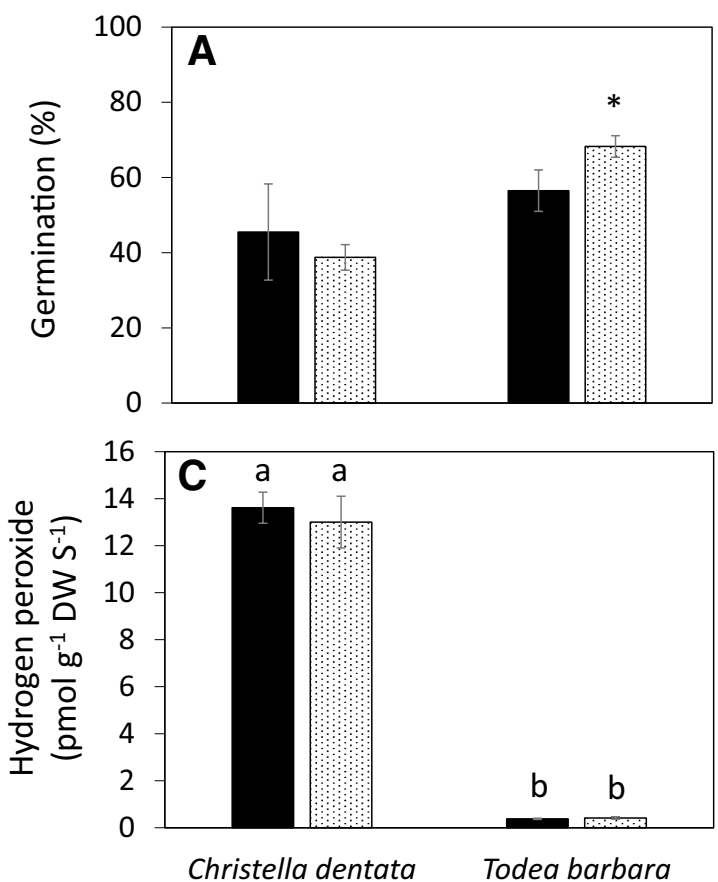

Fig. 3 Germination (a), TAA (b), extracellular hydrogen peroxide levels (c), and levels of superoxide (d) for spores of T. barbara and $C$. dentata before (black bars) and after (dotted bars) equilibration drying for $24 \mathrm{~h}$ at $15 \% \mathrm{RH}$ and $4{ }^{\circ} \mathrm{C}$. Asterisk in (a) indicate the ger-

germination decreased significantly $(\mathrm{P}<0.001)$ for both species in both storage conditions. The GLM model used also allowed us to calculate time to reduce to $50 \%$ initial germination (P50) which was $79 \pm 12$ days for $C$. dentata in the dark and $310 \pm 271$ days in the light, $26 \pm 1$ days for $T$. barbara in the dark and $15 \pm 1$ days in the light.

\section{ROS levels and TAA activity during desiccation of fern spores}

Oxidative status of green and non-green spores before and after drying was measured in terms of extracellular $\mathrm{O}_{2}{ }^{--}$and $\mathrm{H}_{2} \mathrm{O}_{2}$ production, and TAA activity. Superoxide and $\mathrm{H}_{2} \mathrm{O}_{2}$ levels, as well as TAA activity were significantly different between species for both moisture conditions $(\mathrm{P}<0.05)$, with the T. barbara spores showing the highest activity of antioxidants and the lowest levels of $\mathrm{O}_{2}^{--}$and $\mathrm{H}_{2} \mathrm{O}_{2}$ (Fig. 3). After drying, levels of $\mathrm{O}_{2}{ }^{--}$, extracellular $\mathrm{H}_{2} \mathrm{O}_{2}$ and antioxidant activity remained unchanged in green spores (Fig. 3b-d). For non-green spores, drying did not affect the levels of $\mathrm{H}_{2} \mathrm{O}_{2}$ and the activity of antioxidants, however, the levels of $\mathrm{O}_{2}{ }^{--}$were significantly increased (Fig. 3d).

When values of $\mathrm{O}_{2}^{--}$, extracellular $\mathrm{H}_{2} \mathrm{O}_{2}$, TAA activity were regressed against the storage time, in green spores, $\mathrm{O}_{2}{ }^{--}$levels and TAA activity in both light and dark conditions tended to decrease with time, as well as extracellular

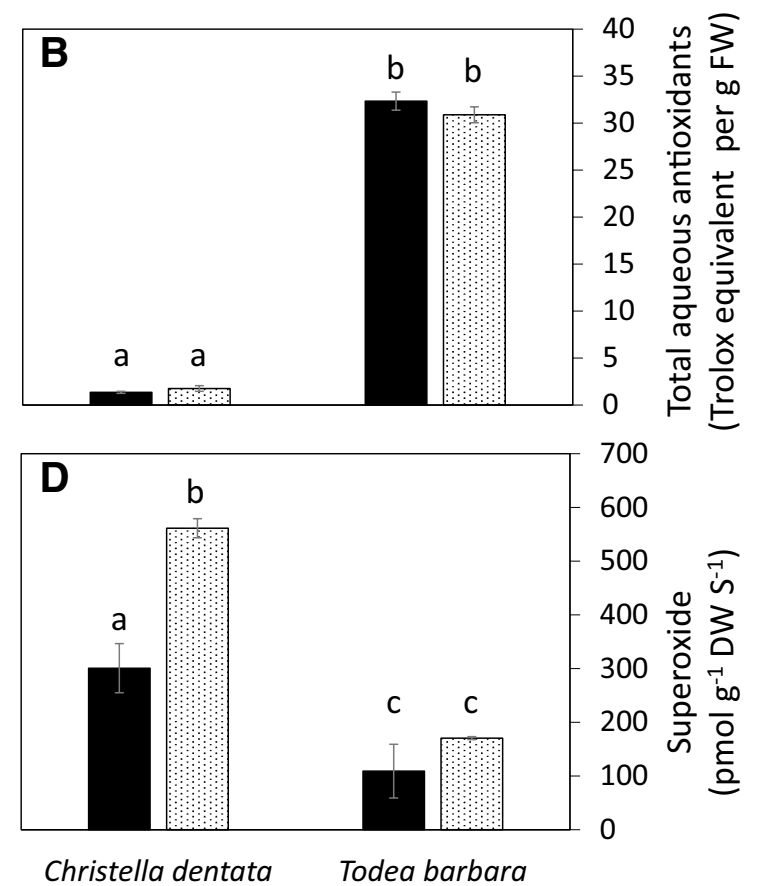

mination between spores before and after drying were significantly different for a particular species $(\mathrm{P}<0.05$, T-test). Different letters indicate that levels of ROS and TAA were significantly different between species for both drying conditions $(\mathrm{P}<0.05$, ANOVA)

$\mathrm{H}_{2} \mathrm{O}_{2}$ levels in dark-stored spores (Table 1, negative slopes). However, none of these regressions were statistically significant $(\mathrm{P}>0.05$, Table 1). On the other hand, extracellular $\mathrm{H}_{2} \mathrm{O}_{2}$ levels of light-stored spores increased significantly with the time ( $\mathrm{P}=0.043$, Table 1). In non-green spores, levels of $\mathrm{O}_{2}{ }^{-}$and TAA activity in both light and dark conditions, and extracellular $\mathrm{H}_{2} \mathrm{O}_{2}$ levels in light-stored spores tended to decrease with the time (Table 1 , negative slopes). Conversely, levels of extracellular $\mathrm{H}_{2} \mathrm{O}_{2}$ tended to increase

Table 1 Summary of regressions and stats for ROS and TAA over time

\begin{tabular}{|c|c|c|c|c|}
\hline & \multicolumn{2}{|l|}{ Dark } & \multicolumn{2}{|l|}{ Light } \\
\hline & Slope \pm SD & Prob & Slope \pm SD & Prob \\
\hline \multicolumn{5}{|l|}{ Christella dentata } \\
\hline Superoxide & $-0.09 \pm 0.02$ & NS & $-0.05 \pm 0.03$ & NS \\
\hline Hydrogen peroxide & $1.3 \pm 1.9$ & NS & $-4.2 \pm 1.6$ & NS \\
\hline $\begin{array}{l}\text { Total aqueous antioxi- } \\
\text { dants }\end{array}$ & $-34 \pm 8$ & 0.047 & $-12 \pm 15$ & NS \\
\hline \multicolumn{5}{|l|}{ Todea barbara } \\
\hline Superoxide & $-0.28 \pm 0.09$ & NS & $-0.37 \pm 0.11$ & NS \\
\hline Hydrogen peroxide & $-103 \pm 65$ & NS & $22 \pm 5$ & 0.043 \\
\hline $\begin{array}{l}\text { Total aqueous antioxi- } \\
\text { dants }\end{array}$ & $-2.5 \pm 1.7$ & NS & $-1.1 \pm 1.0$ & NS \\
\hline
\end{tabular}


in non-green spores stored in the dark. However, none of the regressions were statistically significant $(\mathrm{P}>0.05$, Table 1$)$, except for TAA activity in non-green spores stored in the dark $(\mathrm{P}=0.047$, Table 1). Furthermore, when comparisons were made within species across storage times, $\mathrm{O}_{2}{ }^{--}$levels in green spores were significantly reduced relative to time zero on day 13 when stored in the dark and in green spores stored in both light and dark on day 41 (Fig. 4a). In green spores, $\mathrm{O}_{2}{ }^{--}$levels did not significantly differ between light and dark conditions within storage times (Fig. 4a). Levels of extracellular $\mathrm{H}_{2} \mathrm{O}_{2}$ in green spores did not change significantly along with storage time, except for light-stored spores on day 41 in which levels were significantly higher than time zero (Fig. 4c). This burst of $\mathrm{H}_{2} \mathrm{O}_{2}$ was coincident with a very low germination percentage (see Fig. 2). TAA activity was significantly reduced relative to time zero in all storage times and conditions in green spores (Fig. 4e). In addition, TAA activity was significantly lower in spores stored in the light than in spores stored in the dark for all the storage times (Fig. 4e). For non-green spores, except for dark-stored spores on day $2, \mathrm{O}_{2}{ }^{--}$levels were significantly reduced in all storage times and conditions relative to time zero; this reduction was most severe in non-green spores stored in the light for 2 and 13 days when compared to levels in spores stored in the dark on those days (Fig. 4b).

Additionally, $\mathrm{H}_{2} \mathrm{O}_{2}$ levels were not higher than time zero during storage in non-green spores. In fact, levels were significantly lower than time zero in dark-stored spores on day 2 and light-stored spores on day 41 (Fig. 4d). Except for light-stored spores on day 2 and dark-stored spores on day 41 , activity of TAA were also not significantly reduced relative to time zero across storage times and conditions in nongreen spores (Fig. 4f).

\section{Physical status of fern spore cytoplasm before and after drying}

DSC scans were performed for green and non-green spores at various water contents (data not shown). Exothermic events were detected in cooling scans as peaks between -5 and $-80^{\circ} \mathrm{C}$ and identified as TAG crystallization transitions (after Ballesteros and Walters 2007b) (scans not shown).
Fig. 4 Levels of superoxide $(\mathbf{a}, \mathbf{b})$, extracellular hydrogen peroxide (c, d), and TAA (e, f) for spores of T. barbara $(\mathbf{a}, \mathbf{c}$, $\mathbf{e , ~} \mathbf{g})$ and $C$. dentata $(\mathbf{b}, \mathbf{d}, \mathbf{f}, \mathbf{h})$ stored in the dark (grey bars) or in the light (white bars). Asterisks indicate the levels for each storage time and condition that are significantly different from the levels of spores after initial equilibration drying (dotted bar in Fig. 3) ( $\mathrm{P}<0.05$, ANOVA). Hash indicate that levels are significantly different $(\mathrm{P}<0.05$, T-test) between dark and light conditions for a particular storage time
Todea barbara
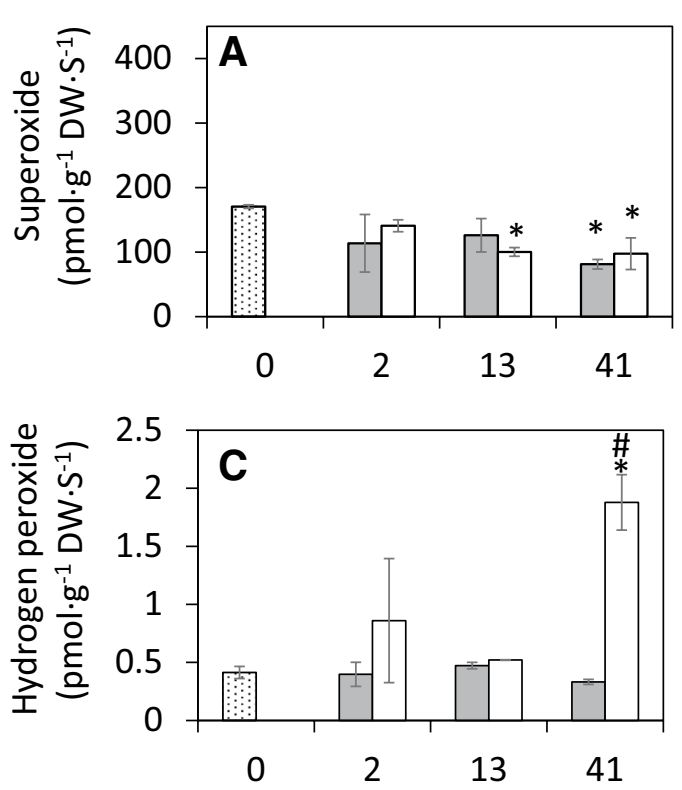

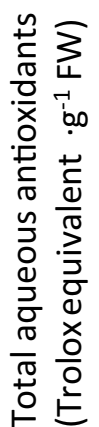

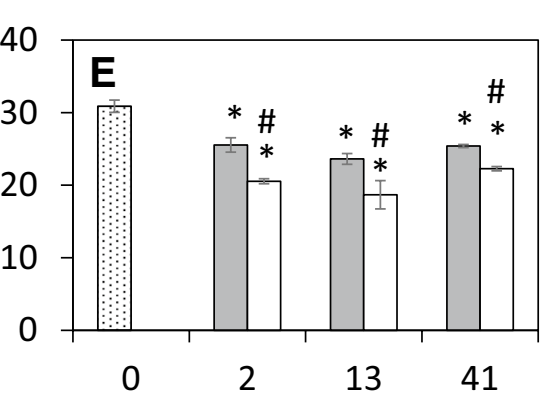

Christella dentata
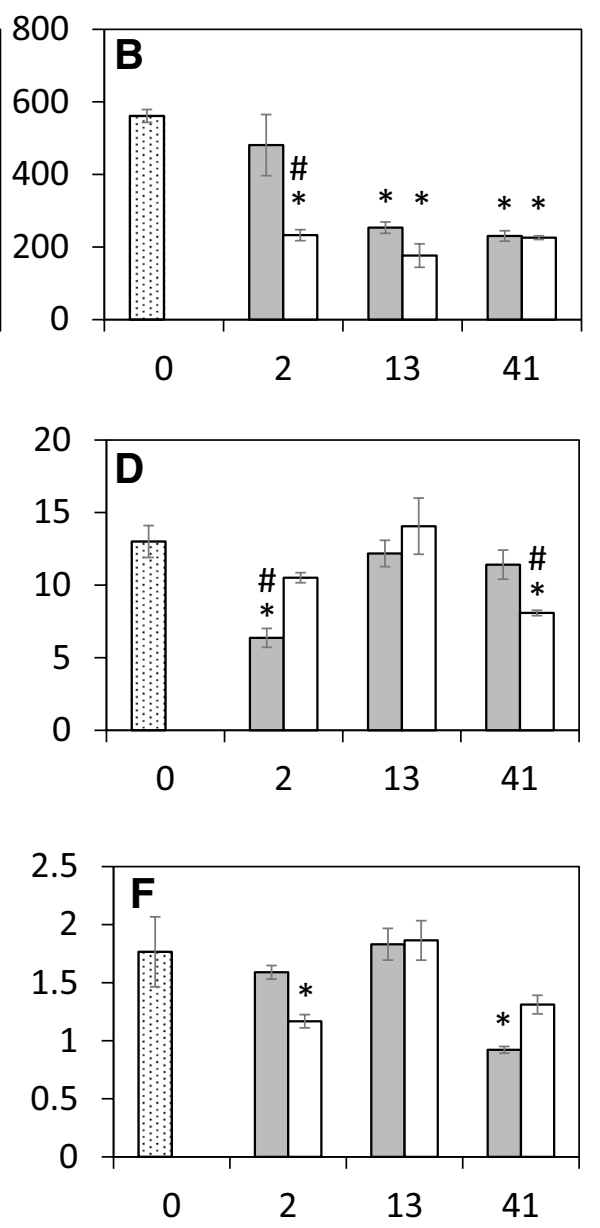
Endothermic events were detected in heating scans as peaks between -20 and $+15{ }^{\circ} \mathrm{C}$ and identified as TAG melting transitions (after Ballesteros and Walters 2007b) (Fig. 5 shows spores dried at $13 \% \mathrm{RH}$ to $0.03-0.04 \mathrm{~g} \mathrm{~g}^{-1}$, TAG melt is indicated by black arrows). TAG melting transitions were larger in non-green spores than in green spores. The size and temperature of the TAG melting transitions allowed us to predict the predominant fatty acid of the TAG and estimate the lipid content for the diverse species (after Ballesteros and Walters 2007b). Based on the melting temperatures, the lipids in the spores were predicted to contain mostly linoleic acid for $C$. dentata or mostly oleic acid for $T$. barbara (Table 2). Lipid contents were estimated to be 32 and 5\% for the non-green spores of $C$. dentata and green spores of T. barbara, respectively (Table 2). Second order transitions, identified as Tg (see "Materials and methods"), were also detected in green and non-green spores (Fig. 5), but these were barely detectable in the non-green spores as they were

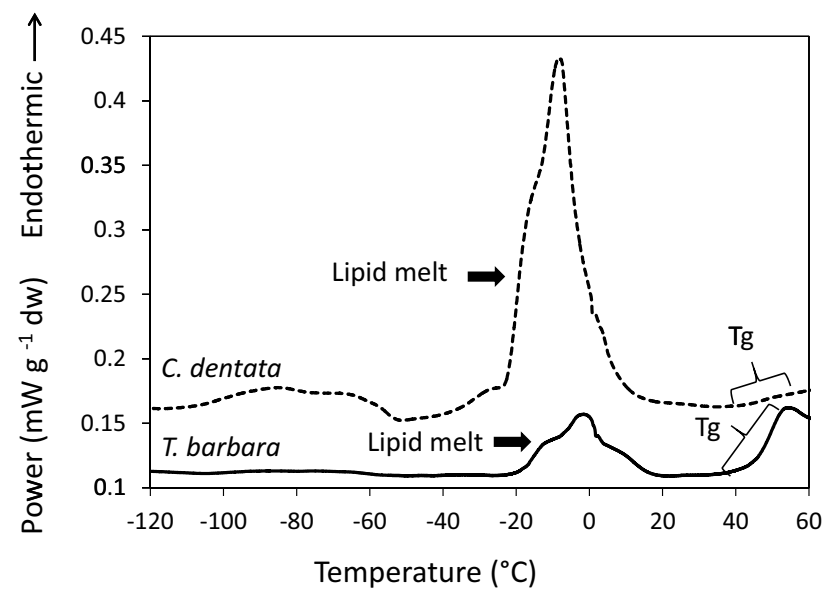

Fig. 5 Representative DSC scans used to calculate TAG melting and glass transitions temperature ( $\mathrm{Tg}$ ) in $T$. barbara and $C$. dentata spores equilibrated at $13 \% \mathrm{RH}$ and $20{ }^{\circ} \mathrm{C}$ (about $0.03 \mathrm{~g} \mathrm{H}_{2} \mathrm{O} \mathrm{g}^{-1} \mathrm{DW}$ ) small and occurred over a broad temperature range, interfering with the TAG melting signal. For both species, phase diagrams with lipid melting and Tg information obtained from the DSC scans (Fig. 6) show that spores went through a process of vitrification (solidification of the cytoplasm) during drying (grey arrow), and were stored in the glass (solid cytoplasm) state during the storage experiment (grey box). Under these conditions storage lipids (TAG) appear to have been in a fluid state were in a fluid state.

\section{Discussion}

Plant propagules tolerant to desiccation age and die when in the dry state at a rate dependent on physicochemical characteristics determined by the moisture content and temperature during storage, as well as by the genotype and the phenotype expressed after development of the propagule (Walters 1998; Walters et al. 2010; Arif et al. 2017; Pereira Lima et al. 2017). Green (or chlorophyllous) spores generally age faster than non-green (or non-chlorophyllous) spores (Lloyd and Klekowski 1970; Ballesteros et al. 2017), and in this study we aimed to understand some of the mechanisms that may lead to this differential ageing in the dry state. At present, little is known about the mechanisms that confer DT and longevity to fern spores in the dry state (Ballesteros 2010; Ballesteros et al. 2017). Due to the different cellular composition between green and non-green spores (i.e. the presence of chlorophyll in green spores), we hypothesized that the exacerbation of oxidative stress typically associated with exposure to light could be responsible for the fast ageing of green spores. Similar findings have been reported for other dry chlorophyllous propagules such as Salix nigra seeds (Roqueiro et al. 2010). Results of the present study show that when stored dry, green spores aged more rapidly than non-green spores under both light and dark conditions, but for green spores this ageing was exacerbated by
Table 2 A summary of the calorimetric properties measured for lipid and water in fern spores

\begin{tabular}{lll}
\hline & Christella dentata & Todea barbara \\
\hline Spore type & Non-green & Green \\
Lipid & & \\
Crystallization temperature $\left({ }^{\circ} \mathrm{C}\right)$ & $-14.1 \pm 0.5$ & $-6.9 \pm 0.4$ \\
Melting temperature $\left({ }^{\circ} \mathrm{C}\right)$ & $-22.1 \pm 1.3$ & $-14.6 \pm 0.9$ \\
Melting enthalpy $\left(\mathrm{J} \mathrm{g}^{-1} \mathrm{DW}\right)$ & $27.5 \pm 3.4$ & $4.7 \pm 0.7$ \\
Predominant fatty acid $\left(\mathrm{predicted}^{-1}\right.$ & Linoleic & Oleic \\
Enthalpy of melt $\mathrm{J} \mathrm{g}^{-1}$ lipid & \\
Lipid content $\%\left(\mathrm{estimated}^{\mathrm{a}}\right)$ & 88 & 100 \\
$\mathrm{Tg}$ & 32 & 5 \\
Water content $\left(\mathrm{g} \mathrm{H}_{2} \mathrm{O} \mathrm{g}{ }^{-1} \mathrm{DW}\right)$ at $20{ }^{\circ} \mathrm{C}$ & & 0.06 \\
Relative humidity $(\%)$ at $20{ }^{\circ} \mathrm{C}$ & 0.06 & 38 \\
\hline
\end{tabular}

${ }^{a}$ Ballesteros and Walters (2007b) 


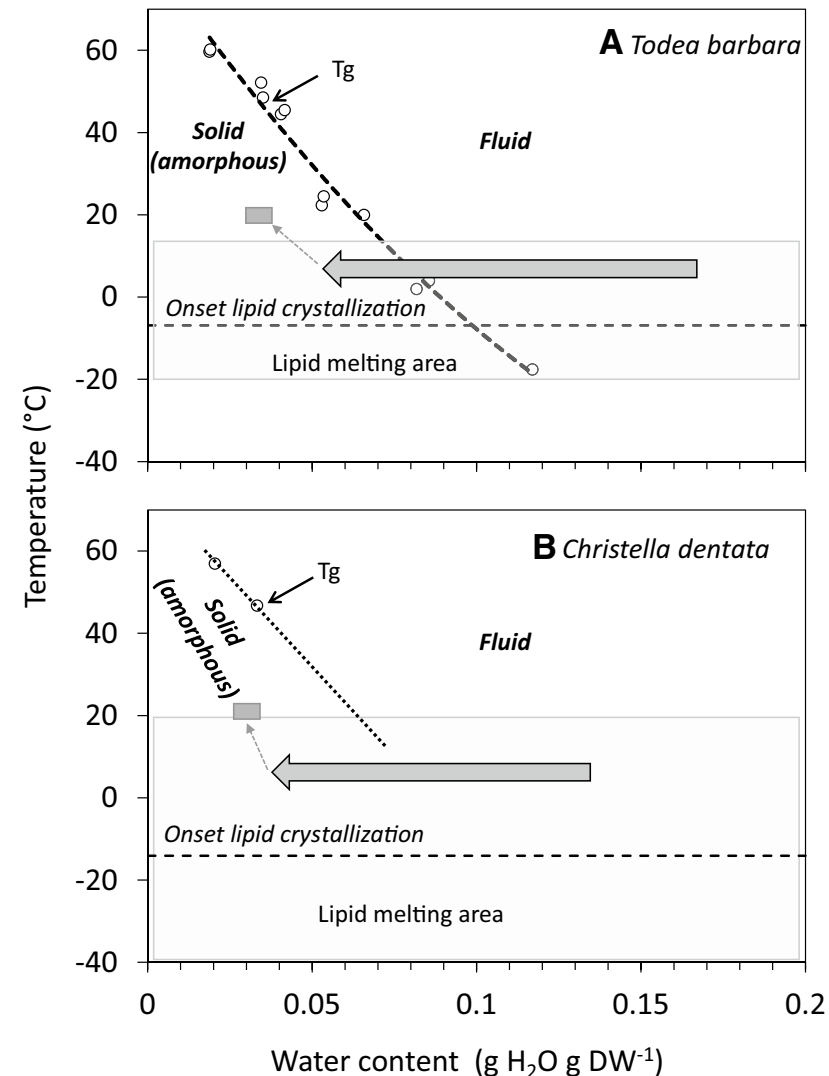

Fig. 6 Phase diagram showing the biophysical status of T. barbara (a) and $C$. dentata (b) spores before and after drying to the moisture conditions used for dry storage. Grey arrow indicates the water content change during drying, and the grey box the conditions during storage. A second order polynomial line (dashed line) was used to represent the relation between the glass transition temperature (Tg) and the water content in T. barbara spores. The TAG melting signal masked the $\mathrm{Tg}$ signal for the non-green spores of $C$. dentata at water contents above $0.04 \mathrm{~g} \mathrm{H}_{2} \mathrm{O} \mathrm{g}^{-1} \mathrm{DW}$, and $\mathrm{Tg}$ was impossible to calculate. For this reason, the dotted line in (b) represents an estimation on the relation of $\mathrm{Tg}$ and water content. The onset for lipid crystallization is indicated by a horizontal dashed line. The shaded area is the temperature range where lipid melting transitions were detected

light (Fig. 2). This rapid ageing in light-stored spores was associated with lower TAA activity (relative to time zero and dark-stored spores) during storage, and a burst of $\mathrm{H}_{2} \mathrm{O}_{2}$ during the latter stages of storage, which was not a feature of dark-stored spores (Fig. 4). We attribute these signs of enhanced oxidative-stress mediated ageing in light-stored spores to photo-oxidative processes.

Interestingly, there were large differences in TAA activity and ROS levels between green and non-green spores immediately after harvest, with green-spores possessing higher TAA activity and lower ROS levels than non-green spores [ca. 15 fold higher TAA activity and 3-30 fold lower ROS levels in green than non-green spores (Fig. 3)]. These results suggest that the two spore types differ in terms of their developmental and, possibly, in terms in their oxidative responses to drying to $15 \% \mathrm{RH}$, i.e. transition from fluid to solid (i.e. glassy) state. Also, while drying appeared to enhance germination in green spores, drying had no significant effect on germination in non-green spores despite a rise in $\mathrm{O}_{2}{ }^{--}$production (Fig. 3). This could represent an afterripening response in green spores but no previous reports of this phenomenon exist in the literature and this observation deserves further investigation. Increased post-harvest germination percentages of fern spores in comparison to those obtained for freshly harvested spores have been observed in spores stored in hydrated conditions (Quintanilla et al. 2002) or after liquid nitrogen exposure (Filipin et al. 2017). In these two situations the increased germination performance has been related to an artefact of faster germination of hydrated spores and incomplete germination time courses for freshly harvested spores (Quintanilla et al. 2002) or to liquid nitrogen induced scarification that facilitated water imbibition and subsequent germination (Filipin et al. 2017).

The high TAA activity and low ROS levels of green spores compared with non-green spores suggests differing mechanisms of coping with life in the dry state, and probably differing ageing mechanisms. High activity of TAA in green spores at shedding, could be responsible for the low initial levels of ROS in green spores. One could expect green spores to possess greater protection against oxidative stress given their susceptibility to photo-oxidative damage, as in other plants. For example, the accumulation of antioxidant molecules during drying is typical for diverse homoiochlorophyllous plants, i.e. desiccation tolerant organisms (e.g. lichens, bryophytes, resurrection plants) that have to cope with chlorophyll in the dry state and need photo-protection during life in the dry state (Kranner et al. 2002, 2008; Heber et al. 2006; Farrant et al. 2009). This could have been the case of green spores in this study, which during maturation/ drying in the sporangia, or right after dispersal, accumulate high levels of TAA to cope with the light-associated risks posed by the chlorophyll molecules they contain when dispersed in the dry state.

However, this superior antioxidant protection does not appear to be long-lasting in green spores since they aged 4-20 fold faster (based on P50 values) than non-green spores, irrespective of whether they were stored in light or dark (Fig. 2). As alluded to earlier, this in-storage loss of germinability in green spores was accompanied by a reduction in TAA activity, which was more severe under light conditions. Homoiochlorophyllous plants have been reported to lose antioxidant capacity during life in the dry state, and this loss generally leads to the inability to recover upon rehydration (Kranner et al. 2002; Illing et al. 2005; Farrant 2007). This sustained reduction in TAA activity during dry storage of green spores when accompanied by light conditions (Fig. 4e), may have led to the burst of $\mathrm{H}_{2} \mathrm{O}_{2}$ observed on day 42 in light-stored green spores. These results also allow us 
to speculate that the inability to recover from losses of photosystem II (PSII) core function upon rehydration, as time in the dry state progressed in the green spores of E. hyemale (Lebkuecher 1997), could be related to an accumulation of oxidative damage in dry spores. Light is absorbed by the pigments of the photosynthetic apparatus of such spores when they are stored dry, and it is known that when water is absent, parts of PSII threaten to oxidise components of the photosynthetic apparatus, particularly when the antioxidant machinery is depleted (Kranner et al. 2002, 2008; Illing et al. 2005; Heber et al. 2006; Farrant 2007). An improved understanding of the ageing mechanisms of green spores during dry storage could therefore benefit from an investigation of the activity of specific (particularly enzymic) antioxidants in these spore in relation to the loss of function of the photosystems (Lebkuecher 1997; Kranner and Birtic 2005).

On the other hand, non-green spores can be linked to poikilochlorophyllous organisms (Kranner et al. 2002), i.e. those that lose all their chlorophyll as the photosynthetic apparatus is dismantled during desiccation (or in this case, during spore maturation). This strategy avoids free radical formation caused by the excitation of the chlorophyll in the dry state and this may explain the relatively slower ageing in non-green spores in this study, which was accompanied by a decrease in ROS levels relative to time zero and the absence of a sustained decrease in TAA activity during storage. It should be noted though that the time frame used for storage in this study (42 days) was relatively short and this may explain why no large decrease in germination was observed for non-green spores and this could have influenced longevity estimations. The difference in longevity between lightand in the dark-stored non-green spores could also be an artefact of the short storage time.

Mechanisms of ageing during dry storage of spores are understudied. Beri and Bir (1993) suggested that ageing of the non-green spores of Pteris vittata was related to the loss of soluble substances such as sugars, proteins and free amino acids during storage, which ultimately leads to lower water uptake upon imbibition. However, the loss of these soluble substances during storage seems unlikely when the cytoplasm is in a glassy state (as is the case of the spores in this work, Fig. 6) and molecular mobility is largely reduced (Walters et al. 2010; Ballesteros and Walters 2011). Alternatively, we suggest an ageing mechanism based on the biophysical profile of the spore when dry and the effects of oxidative stress in the aqueous and lipid matrix. The aqueous part of the cytoplasm in spores entered into a solid (glassy) state when dried at room temperature and $<30 \%$ RH (Fig. 6). However, lipids in the cytoplasm were still in a fluid state as crystallization temperatures were -7 and $-14{ }^{\circ} \mathrm{C}$ for green and non-green spores, respectively (Table 2; Fig. 6). This results in a complex biophysical spore profile, in which fluid lipid droplets are surrounded by a solidified cytoplasm, analogous to microencapsulated lipids in glassy matrices used in the food industry (Orlien et al. 2006; Ozbek and Ergonul 2017). This particular physicochemical phenomenon could result in structural instability during storage, leading to collapse as has been described for diverse food systems with solid-fluid combinations (Mayor and Sereno 2004; Ozbek and Ergonul 2017) and could be of importance in non-green spores, considering their high lipid contents [ $32 \%$ for the species studied here; $20-50 \%$ for a range of non-green spores species (Ballesteros and Walters 2007b)]. Additionally, high accumulation of ROS after spore dispersal (as observed in non-green spores in this study) or during long-term dry storage could promote peroxidation of lipid droplets (Andersen and Skibsted 2002) and ultimately ageing modification of their structure and potential to interact with other biomolecules within the solid cytoplasm. The collapse over time of the solid matrix of the cytoplasm, and hence ageing and death has also been hypothesized for other propagules such as seeds (Walters et al. 2010).

\section{Concluding remarks}

While mechanisms of desiccation tolerance and life in the dry state have received much attention in lichens, bryophytes, resurrection plants and seeds, little is known for fern spores. To our knowledge, this study represented the first evidence for the impacts of the interactions among light, pro- and anti-oxidants in dry-stored fern spores on storage longevity. The results together with the findings of Lebkuecher (1997) on damage associated with the photosynthetic apparatus of green spores during dry storage, and Beri and Bir (1993) on the depletion of reserve substances in nongreen spores during dry storage suggest that ageing in ferns spores may be multimechanistic but is influenced by the presence/absence of chlorophyll. The results have a number of implications for $e x$ situ storage of fern spores: (1) spore chlorophyll content should be considered when designing storage methods; (2) longevity during dry storage may be enhanced under dark conditions; (3) dry storage in a reducing atmosphere may enhance storage longevity by reducing ROS-mediated ageing. Finally, fern spores represent a useful unicellular model for understanding desiccation tolerance in plants as ferns represent the bridge between the mechanisms found in bryophytes and those that have evolved in angiosperms.

Acknowledgements This work was made possible through financial support from the National Research Foundation, South Africa (which included a Thuthuka grant awarded to Sershen) and the University of KwaZulu-Natal (Post-doctoral fellowship awarded to Ballesteros).

Author contributions DB, S and BV designed study. SN, BV, DB and S performed experiments. DB, S and BV analyzed the results. DB and S 
wrote the manuscript and BV revised the manuscript. All authors read and approved the manuscript.

\section{Compliance with ethical standards}

Conflict of interest The authors declare that they have no conflict of interest.

Research involving human and animal participants No human participants and/or animals are involved in the research.

Open Access This article is distributed under the terms of the Creative Commons Attribution 4.0 International License (http://creativecommons.org/licenses/by/4.0/), which permits unrestricted use, distribution, and reproduction in any medium, provided you give appropriate credit to the original author(s) and the source, provide a link to the Creative Commons license, and indicate if changes were made.

\section{References}

Andersen ML, Skibsted LH (2002) Detection of early events in lipid oxidation by electron spin resonance spectroscopy. Eur J Lipid Sci Technol 104:65-68

Arif MAR, Nagel M, Lohwasser U, Börner A (2017) Genetic architecture of seed longevity in bread wheat (Triticum aestivum L.). J Biosci 42:81-89

Ballesteros D (2010) Conservation of fern spores. In: Kumar A, Fernández H, Revilla-Bahillo A (eds) Working with ferns. Issues and applications. Springer, New York, pp 165-172

Ballesteros D, Walters C (2007a) Water properties in fern spores: sorption characteristics relating to water affinity, glassy states and storage stability. J Exp Bot 58:1185-1196

Ballesteros D, Walters C (2007b) Calorimetric properties of water and triacylglycerols in fern spores relating to storage at cryogenic temperatures. Cryobiology 55:1-9

Ballesteros D, Walters C (2011) Detailed characterization of mechanical properties and molecular mobility within dry seed glasses: relevance to the physiology of dry biological systems. Plant $\mathrm{J}$ 68:607-619

Ballesteros D, Estrelles E, Walters C, Ibars AM (2011) Effect of storage temperature on green spore longevity for the ferns Equisetum ramosissimum and Osmunda regalis. Cryoletters 32:89-98

Ballesteros D, Estrelles E, Walters C, Ibars AM (2012) Effects of temperature and desiccation on ex situ conservation of non-green fern spores. Am J Bot 99:1-9

Ballesteros D, Hill LM, Walters C (2017) Variation of desiccation tolerance and longevity in fern spores. J Plant Physiol 211:53-62

Beri A, Bir SS (1993) Germination of stored spores of Pteris vittata L. Am Fern J 833:73-78

Berjak P, Sershen, Varghese B, Pammenter NW (2011) Cathodic amelioration of the adverse effects of oxidative stress accompanying procedures necessary for cryopreservation of embryonic axes of recalcitrant-seeded species. Seed Sci Res 21:187-203

Buitink J, Walters-Vertucci C, Hoekstra FA, Leprince O (1996) Calorimetric properties of dehydrating pollen: analysis of a desiccationtolerant and an intolerant species. Plant Phys 111:235-242

Dyer AF (1979) The culture of fern gametophytes for experimental investigation. In: Dyer AF (ed) The experimental biology of ferns. Academic Press, London, pp 254-305
Farrant JM (2007) Mechanisms of desiccation tolerance in angiosperm resurrection plants. In: Jenks MA, Wood AJ (eds) Plant desiccation tolerance. CABI Press, Wallingford, pp 51-90

Farrant JM, Lehner A, Cooper K, Wiswedel S (2009) Desiccation tolerance in the vegetative tissues of the fern Mohria caffrorum is seasonally regulated. Plant J 57:65-79

Filipin EP, Simioni C, Schmidt EC, Randi AM. \& Fisch (2017) Pleopeltis lepidopteris Langsd. (Polypodiaceae), an endemic fern from Brazilian "restingas": viability of spores under different storage conditions. Braz J Bot 40:59-65

Franchi GG, Piotto B, Nepi M, Baskin CC, Baskin JM, Pacini E (2011) Pollen and seed desiccation tolerance in relation to degree of developmental arrest, dispersal, and survival. J Exp Bot 62:5267-5281

Gaff DF, Oliver M (2013) The evolution of desiccation tolerance in angiosperm plants: a rare yet common phenomenon. Funct Plant Biol 40:315-328

Gay C, Gebicki JM (2000) A critical evaluation of the effect of sorbitol on the ferric-xylenol orange hydroperoxide assay. Anal Biochem 284:217-220

Heber U, Lange OL, Shuvalov VA (2006) Conservation and dissipation of light energy as complementary processes: homiohydric and poikilohydric autotrophs. J Exp Bot 57:1211-1223

Hoekstra FA (2005) Differential longevities in desiccated anhydrobiotic plant systems. Integr Comp Biol 45:725-733

Illing N, Denby K, Collett H, Shen A, Farrant JM (2005) The signature of seeds in resurrection plants: a molecular and physiological comparison of desiccation tolerance in seeds and vegetative tissues. Integ Comp Biol 45:771-787

Kranner I, Birtic S (2005) A modulating role for antioxidants in desiccation tolerance. Integr Comp Biol 45:734-740

Kranner I, Beckett RP, Wornik S, Zorn M, Pfeifhofer HW (2002) Revival of a resurrection plant correlates with its antioxidant status. Plant J 31:13-24

Kranner I, Beckett R, Hochman A, Nash TH III (2008) Desiccationtolerance in lichens: a review. The Bryologist 111:576-593

Kranner I, Minibayeva FV, Beckett RP, Seal CE (2010) What is stress? Concepts, definitions and applications in seed science. New Phytol 188:655-673

Lebkuecher JG (1997) Desiccation-time limits of photosynthetic recovery in Equisetum hyemale (Equisetaceae) spores. Am J Bot 84:792-797

Leprince O, Buitink J (2010) Desiccation tolerance: from genomics to the field. Plant Sci 179:554-564

Leprince O, Buitink J (2015) Introduction to desiccation biology: from old borders to new frontiers. Planta 242:369-378

Li Y, Shi L (2014) Effect of desiccation level and storage temperature on green spore viability of Osmunda japonica. Cryobiology $68: 446-450$

Li Y, Shi L (2015) Effect of maturity level and desiccation process on liquid nitrogen storage of green spores of Osmunda japonica. Plant Cell Tissue Organ Cult 120:531-538

Lloyd RM, Klekowski EJ Jr (1970) Spore germination and viability in Pteridophyta: evolutionary significance of chlorophyllous spores. Biotropica 2:129-137

Mayor L, Sereno AM (2004) Modelling shrinkage during convective drying of food materials: a review. J Food Eng 61:373-386

Misra HP, Fridovich I (1972) The role of superoxide anion in the autoxidation of epinephrine and a simple assay for superoxide dismutase. J Biol Chem 247:3170-3175

Orlien V, Risbo J, Rantanen H, Skibsted LH (2006) Temperature -dependence of rate oxidation rapeseed oil encapsulated in a glassy food matrix. Food Chem 94:37-46

Özbek A, Ergönül PG (2017) A review on encapsulation of oils. CBU J Sci 13:293-309 
Pence V (2000) Survival of Chlorophyllous and Nonchlorophyllous Fern Spores through Exposure to Liquid Nitrogen. Am Fern J 90:119-126

Pereira Lima JJ, Buitink J, Lalanne D, Rossi RF, Pelletier S, da Silva EAA et al (2017) Molecular characterization of the acquisition of longevity during seed maturation in soybean. PLoS ONE 12(7): 0180282

Quintanilla LG, Amigo J, Pangua E, Pajaron S (2002) Effect of storage method on spore viability in five globally threatened fern species. Ann Bot 90:461-467

Re R, Pellegrini N, Proteggente A, Pannala A, Yang M, RiceEvans CA (1999) Antioxidant activity applying an improved ABTS radical cation decolorization assay. Free Rad Biol Med 26:1231-1237

Roqueiro G, Facorro GB, Huarte MG, de Celis ER, Garcia F, Maldonado S, Maroder H (2010) Effects of photooxidation on membrane integrity in Salix nigra seeds. Ann Bot 105:1027-1034

Sundue M, Vasco A, Moran RC (2011) Cryptochlorophyllous spores in ferns: nongreen spores that contain chlorophyll. Int J Plant Sci 172:1110-1119

Varghese B, Sershen, Berjak P, Varghese D, Pammenter NW (2011) Differential drying rates of recalcitrant Trichilia dregeana embryonic axes: a study of survival and oxidative stress metabolism. Physiol Plant 142:326-338

Verdier J, Lalanne D, Pelletier S, Torres-Jerez I, Righetti K, Bandyopadhyay K, Leprince O, Chatelain E, Vu BL, Gouzy J, Gamas P, Udvardi MK, Buitink J (2013) A regulatory network-based approach dissects late maturation processes related to the acquisition of desiccation tolerance and longevity of Medicago truncatula seeds. Plant Phys 163:757-774

Walters C (1998) Understanding the mechanisms and kinetics of seed ageing. Seed Sci Res 8:223-244

Walters C (2015) Orthodoxy, recalcitrance and in-between: describing variation in seed storage characteristics using threshold responses to water loss. Planta 242:397-406

Walters C, Hill LM, Wheeler LJ (2005) Dying while dry: kinetics and mechanisms of deterioration in desiccated organisms. Integr Comp Biol 45:751-758

Walters C, Ballesteros D, Vertucci VA (2010) Structural mechanics of seed deterioration: standing the test of time. Plant Sci 179:565-573 